\title{
A New Electromagnetic Actuation System on an Industrial Sewing Machine with On-Line Efficiency Monitoring
}

\author{
Luís F. Silva ${ }^{(1)}$, Mário Lima ${ }^{(1)}$, Fernando N. Ferreira ${ }^{(2)}$, \\ Ana M. Rocha ${ }^{(2)}{ }$ Helder Carvalho $^{(2)}$, Carlos Couto ${ }^{(3)}$ \\ ${ }^{(1)}$ Dep. of Mech. Eng. ${ }^{(2)}$ Dep. of Textile Eng. ${ }^{(3)}$ Dep. of Ind. Electronics, School of Eng. \\ University of Minho, Campus de Azurém, 4800-058 Guimarães, Portugal \\ Tel: 351253 510226, Fax: 351253 516007, mlima@dem.uminho.pt
}

\begin{abstract}
This paper briefly reviews the study to evaluate the standard presser foot performance and a new actuation set-up to avoid the bouncing and the lack of fabric control. The compression force and displacement waveforms are also presented and widely discussed, as well as the seam's quality analysis. A spectral (Fast Fourier Transform and Harmonic Distortion) analysis on the obtained waveforms, as well as an Admissible Displacement Limits (ADL) analysis are also described as important techniques to be used to supervise the presser foot force and to monitor the feeding efficiency. ADL have proved to be a better method. Further research should be undertaken in this area, in order to achieve, in a near future, a closed loop control of the presser foot.
\end{abstract}

\section{INTRODUCTION}

The feeding system of an overlock sewing machine is made up by a presser foot, a throat plate and a feed dog. At high sewing speeds the presser foot "bounces" and loses contact with the fabric plies resulting on an irregular stitch. To study and evaluate its dynamic behaviour, a "sewability" tester was first developed by Rocha, et al. (Rocha, 1996), and later improved by Carvalho and Ferreira (Carvalho, 1996), and Carvalho, et al. (Carvalho, 1997 \& 2000). An industrial overlock sewing machine was instrumented with miniature piezoelectric force transducers on the presser foot and needle bars, encoders and semiconductor strain gauge transducers on the threads' path. A LVDT for real-time monitoring the movement of the presser foot bar led to further understanding the system dynamics. Figure 1 shows typical presser foot bar displacement waveforms obtained with two plies of a jersey fabric, using a presser foot force of $20 \mathrm{~N}$, a uniform feed and a stitch density of 4 stitches per $\mathrm{cm}$. The beginning of the stitch cycle (0 degrees) is set when the needle is at its lowest position, after fabric penetration. The compression force waveforms obtained with two plies of the same jersey fabric are presented in figure 2 and show, during the feeding period (between 80 and 260 degrees), wide variations with the increase of machine speed (in stitches per minute, spm). At 260 degrees the final peak forces indicate the instant when the presser foot re-establishes contact with the throat plate.

These force variations suggest that the spring forces are not adequate to guarantee an efficient contact between the presser foot and the fabrics. Both contact losses highlighted in figure 1 (at the topmost position of the feed dog above the throat plate level - peak 1 - and soon after the feed dog has been lowered beneath the same level - peak 2 -) occur in all fabrics sewn when the compression forces 
show a tendency to decrease, during and after the feeding process respectively. Therefore, a precise and accurate control of the fabric plies is essential to reduce, or even eliminate, the loss of feeding efficiency that reduces the quality of the seams (Silva, 1999) \& (Silva, 1999).

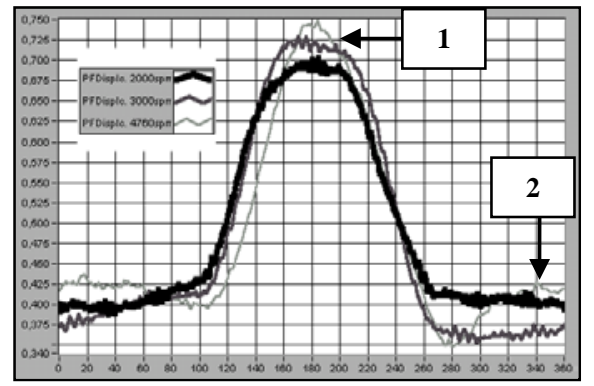

Figure 1 - Horizontal axis: stitch cycle (degrees); Vertical axis: presser bar displacement (mm)

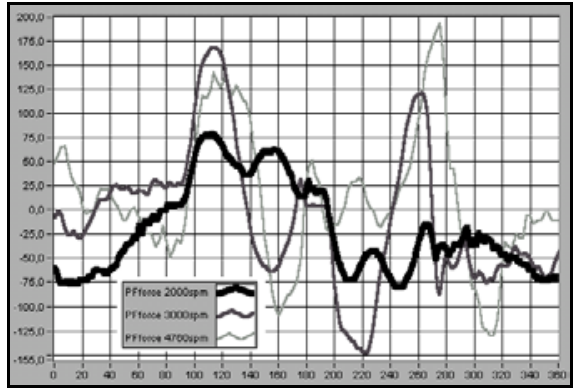

Figure 2 - Horizontal axis: stitch cycle (degrees); Vertical axis: presser bar compression force, relative values (gf)

\section{EXPERIMENTAL SET-UP AND PROCEDURE}

A proportional force solenoid was found to be the most suitable in order to achieve

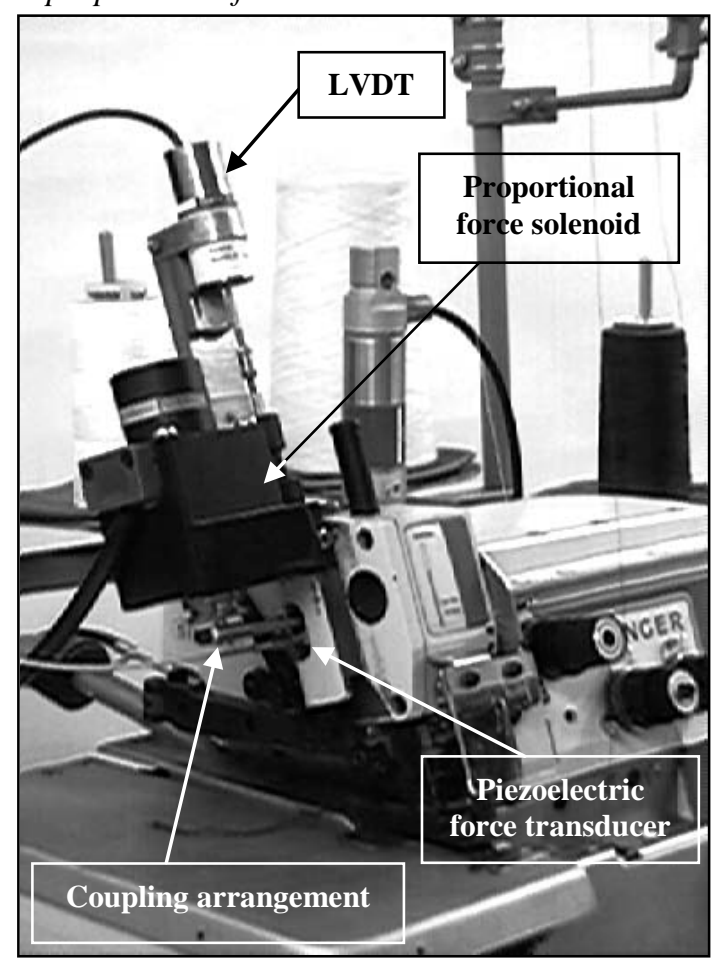

Figure 3 - The presser foot actuation set-up with the proportional force solenoid attached to the presser bar the desired presser foot dynamic behaviour (Silva, 1999). This actuator replaced the standard helical spring, without modifying the arrangement of the force and displacement transducers already included in the previous phase -figure 3 .

Experiments were carried out at different machine speeds. Two plies of three different knit fabrics were used (jersey, interlock and rib $1 \times 1$ ) and two operating conditions were tested: (1) With and (2) Without the helical spring. The other machine settings were kept unchanged throughout the experiments. The actuator, presenting a constant force characteristic (independent of the displacement) will be working in a "continuous" mode, emulating a spring with programmable reaction force. The current to drive the solenoid, to apply an additional or total force, was correlated with the wide force variations observed for all tested fabrics. 


\section{RESULTS AND DISCUSSION}

\subsection{Using the Solenoid and the Helical Spring}

Figures 4 and 5 show, respectively, the presser foot bar displacement and compression force waveforms obtained at 2000, 3000 and 4700spm with the jersey fabric. It is clear that the two contact losses observed in figure 1 (peak 1 and 2) have completely disappeared and the plies are under control, not only in the feeding period but also after the feed dog has been lowered beneath the throat plate level.

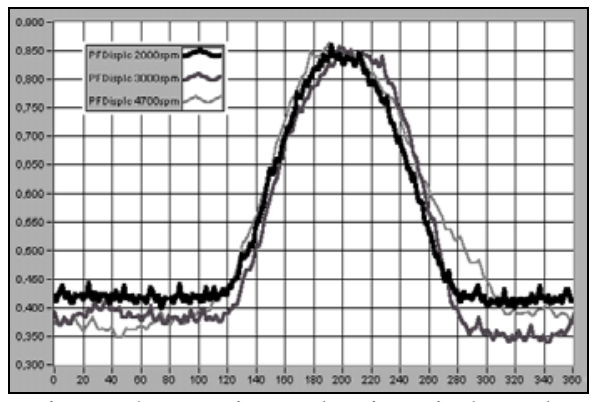

Figure 4 - Horizontal axis: stitch cycle (degrees); Vertical axis: presser bar displacement $(\mathrm{mm})$

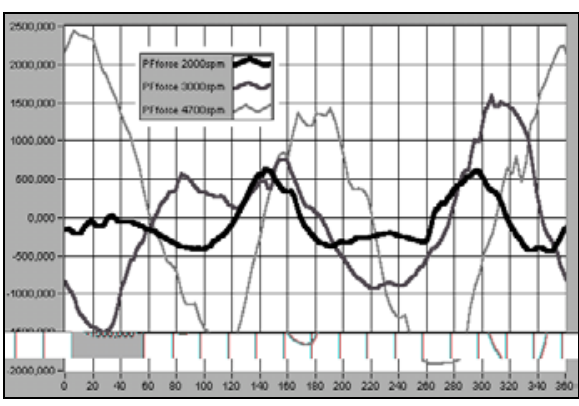

Figure 5 - Horizontal axis: stitch cycle (degrees); Vertical axis: presser bar compression force, relative values (gf)

In terms of compression force, figure 5 also shows a different waveform when compared with figure 2. The feeding period is well defined, showing a force increase with machine speed. The solenoid has now the presser foot under control between its maximum velocity point and the topmost position of the feed dog above the throat plate, where a large negative acceleration peak was previously observed see (Silva, 1999) for further details -, resulting on contact losses detected in figure 1 (peak 1). After this period, a second force peak is surely responsible for holding the fabrics firmly against the throat plate, where a second higher possibility for a contact loss may occur, as another negative acceleration peak was observed, which corresponds to peak 2 in figure 1. This important peak also increases with machine speed.

\subsection{Using the Solenoid}

Once again, no contact losses have been observed for the jersey fabric - see figure 6 . Figure 7 shows the corresponding presser foot bar compression force waveforms obtained for the same machine speeds. The feeding period is better defined and clearly without the wide force variations shown in figure 2.

At 4700spm (figure 6), the decrease of the maximum displacement and the fabrics' compression occurred after feeding, was probably caused by applying a force slightly higher than the amount required for controlling the jersey plies; this same effect has also been observed for the other two fabrics. To test this hypothesis, another set of experiments was carried out for the this same fabric varying the force applied to the presser bar, between $16.70 \mathrm{~N}$ and $23.46 \mathrm{~N}$, which corresponds to a variation of the drive currents between $0.403 \mathrm{~A}$ and $0.503 \mathrm{~A}$. The upper limit equals the force applied by the solenoid at this same speed. The obtained presser foot bar compression force and displacement waveforms, while testing three different drive currents at 4700spm, are shown in figures 8 and 9, respectively. 


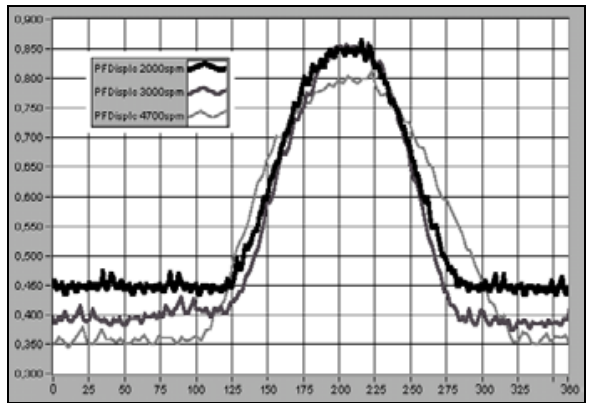

Figure 6 - Horizontal axis: stitch cycle (degrees); Vertical axis: presser bar displacement (mm)

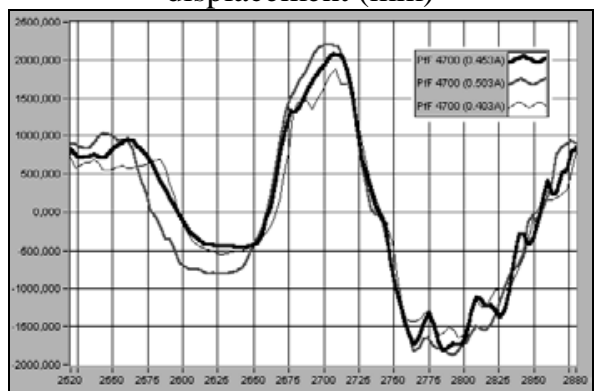

Figure 8 - Horizontal axis: stitch cycle (degrees); Vertical axis: presser bar compression force, relative values (gf)

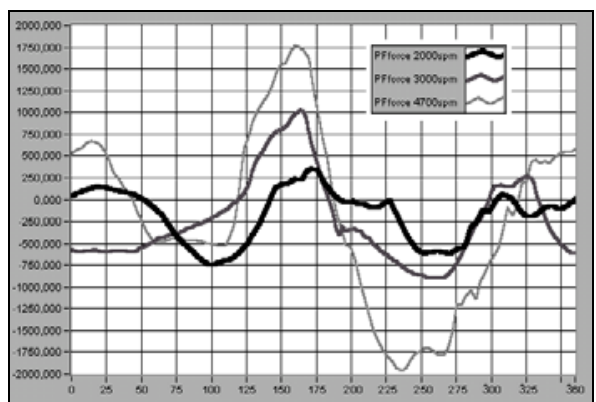

Figure 7 - Horizontal axis: stitch cycle (degrees); Vertical axis: presser bar compression force, relative values (gf)

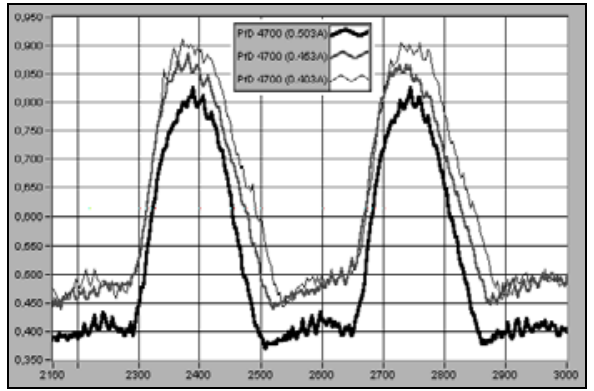

Figure 9 - Horizontal axis: stitch cycle (degrees); Vertical axis: presser bar displacement (mm)

When the force applied to the presser bar decreases, other force variations tend to appear during and after the fabrics feeding. Under these circumstances, the presser foot is unable to guarantee an effective control of the fabric plies, and an increase of the presser foot bar maximum displacement has been observed. When the needle penetrates and withdraws from the fabrics to form the stitch (after the feed dog has been lowered beneath the throat plate), a second displacement also occurs. For the lowest forces, these displacements are even greater than the ones observed in figure 4, using the solenoid and the helical spring, and in figure 6, with only the proportional force solenoid. The waveforms obtained for the other knitted materials (not presented here) revealed exactly the same: the decrease of the forces affects the performance of the presser foot and suggests that the force initially applied provides an effective control of the fabrics.

\subsection{Seams Quality}

An efficient feeding system should be able to guarantee the same stitch density, independently of the fabrics or speeds involved. Ideally, the obtained stitch density should always match the one defined with nominal machine settings. The following tables summarise the mean number of stitches per $\mathrm{cm}$ (spcm) counted over several seams measurements of $5 \mathrm{~cm}$ long for all tested samples.

Using the helical spring on the presser foot bar, the differences between the actual obtained stitch density and the nominal ones increase with machine speed. For the jersey fabric, this loss of efficiency can be explained according to the contact losses observed in figure 1 (peaks 1 and 2). Due to this "bouncing”, the presser foot 
is unable to control the fabrics and the stitch length tends to increase with machine speed, decreasing, therefore, the obtained stitch density - see table 1 . The interlock and rib $1 \times 1$ fabrics show, however, a different sewing behaviour: the stitch densities increase with machine speed, being the maximum difference variations (of $+5.5 \%$ and $+11.5 \%$, respectively) found at $4700 \mathrm{spm}$.

On the other hand, these differences have decreased using the new actuation system, with or without the helical spring. For the jersey fabric (table 1) it can be observed that there is a tendency in both cases to increase the control of fabrics feeding; however, the minimum stitch density differences have been observed with just the solenoid for all tested speeds. These differences have also decreased for the interlock and rib fabrics using only the solenoid on the presser foot bar. Tables 3 and 4 indicate, for $0.502 \mathrm{~A}$, the density variations obtained at $4700 \mathrm{spm}(-0.5 \%$ and $+0.75 \%$, respectively), which represents a huge reduction when compared with the differences already mentioned.

Table 1 - Nominal and actual stitch densities; two plies of a jersey fabric

\begin{tabular}{|c|c|c|c|c|}
\hline System type & $\begin{array}{c}\text { Machine } \\
\text { speed (spm) }\end{array}$ & $\begin{array}{c}\text { Nominal stitch } \\
\text { density (spcm) }\end{array}$ & $\begin{array}{c}\text { Actual stitch } \\
\text { density (spcm) }\end{array}$ & $\begin{array}{c}\text { Variation } \\
(\%)\end{array}$ \\
\hline Helical & 2000 & & 3.80 & -5.0 \\
spring & 3000 & 4 & 3.75 & -6.25 \\
& 4700 & & 3.65 & -8.75 \\
\hline Solenoid & 2000 & & 3.85 & -3.75 \\
and & 3000 & 4 & 3.95 & -1.25 \\
spring & 4700 & & 4.03 & +0.75 \\
\hline \multirow{3}{*}{ Solenoid } & 2000 & & 3.98 & -0.5 \\
& 3000 & 4 & 4.03 & +0.75 \\
& 4700 & & 4.05 & +1.25 \\
\hline
\end{tabular}

Table 2 - Stitch densities; two plies of a jersey fabric changing the drive current

\begin{tabular}{|c|c|c|c|c|}
\hline Current (A) & $\begin{array}{c}\text { Machine } \\
\text { speed (spm) }\end{array}$ & $\begin{array}{c}\text { Nominal stitch } \\
\text { density (spcm) }\end{array}$ & $\begin{array}{c}\text { Actual stitch } \\
\text { density (spcm) }\end{array}$ & Variation (\%) \\
\hline 0.503 & \multirow{3}{*}{4700} & 4 & 4 & 0 \\
0.483 & & & 3.9 & -2.5 \\
0.453 & & & 3.87 & -3.25 \\
0.403 & & & 3.84 & -4.0 \\
\hline
\end{tabular}

The obtained stitch densities varying the drive currents are presented in tables 2, 3 and 4. A decrement of the force applied to the presser foot bar led to the increment of the density differences. These differences show the same tendency as observed before for each fabric using the standard presser foot and are now much smaller. It must be noticed that a null density variation has also been found for the jersey fabric with these set of experiments (see also table 2). These results show that the calculated force (current) gives clearly better results.

Table 3 - Stitch densities; two plies of an interlock fabric changing the drive current

\begin{tabular}{|c|c|c|c|c|}
\hline Current (A) & $\begin{array}{c}\text { Machine } \\
\text { speed (spm) }\end{array}$ & $\begin{array}{c}\text { Nominal stitch } \\
\text { density (spcm) }\end{array}$ & $\begin{array}{c}\text { Actual stitch } \\
\text { density (spcm) }\end{array}$ & Variation (\%) \\
\hline 0.502 & & & 3.98 & -0.5 \\
0.453 & 4700 & 4 & 3.98 & -0.5 \\
0.403 & & & 4.17 & +4.25 \\
\hline
\end{tabular}


Table 4 - Stitch densities; two plies of a rib $1 \times 1$ fabric changing the drive current

\begin{tabular}{|c|c|c|c|c|}
\hline Current (A) & $\begin{array}{c}\text { Machine } \\
\text { speed (spm) }\end{array}$ & $\begin{array}{c}\text { Nominal stitch } \\
\text { density (spcm) }\end{array}$ & $\begin{array}{c}\text { Actual stitch } \\
\text { density (spcm) }\end{array}$ & Variation (\%) \\
\hline 0.502 & \multirow{3}{*}{4700} & 4 & 4.03 & +0.75 \\
0.453 & & 4.08 & +2.0 \\
0.403 & & & 4.16 & +4.0 \\
\hline
\end{tabular}

\section{THE ON-LINE MONITORING OF FEEDING EFFICIENCY}

To provide an alternative perspective to characterise the behaviour of the standard presser foot assembly and the new actuation set-up, a Fast Fourier Transform (FFT) analysis was carried out on the obtained waveforms. This powerful signal analysis tool, included in the software package and developed according to project requirements - see also (Carvalho, 2000) for details and other FFT-related application examples -, was used to translate into the frequency-domain the acquired time-domain signals.

Comparing the obtained displacement spectrums only slight amplitude changes occurred at higher frequency components. Nevertheless, completely different spectrums were observed after processing the presser foot bar compression force waveforms - see figures 10 and 11 for the jersey fabric. The standard spring actuation originates a more spread spectrum harmonics than the solenoid operated one, where it is clear a concentration in the low frequency range. These patterns stand in accordance, respectively, with the wide and quick force variations observed with the helical spring on the presser foot bar and the waveforms acquired using the solenoid, where only two force peaks were detected in the stitch cycle.

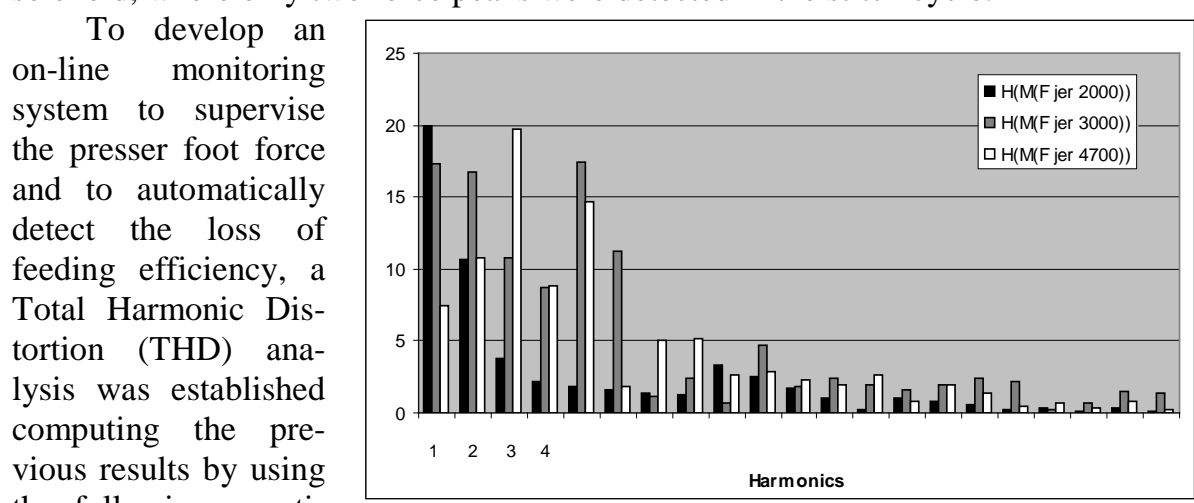
the following equation, where $A_{1}$ and $A_{i}$ correspond to the harmonic amplitudes 1, i:

$$
\text { THD }=\frac{\sqrt{\sum_{\mathrm{i}=2}^{\mathrm{n}} \mathrm{A}_{\mathrm{i}}^{2}}}{\mathrm{~A}_{1}}
$$

This equation was used to determine the THD of the compression force waveforms obtained with the helical spring, while the THD of the other waveforms were determined rearranging the previous equation and considering the amplitude of the double fundamental frequency harmonic as reference, instead of $A_{1}$. (Figure 11 displays this important harmonic component, also observed for the other tested 
fabrics.) The distortion for both cases is presented in figure 12. As expected, the distortion tends to increase with machine speed using the standard presser foot, due to the force variations already mentioned, while the best results were achieved using the actuation set-up of figure 3 with a clear increment of low harmonics.

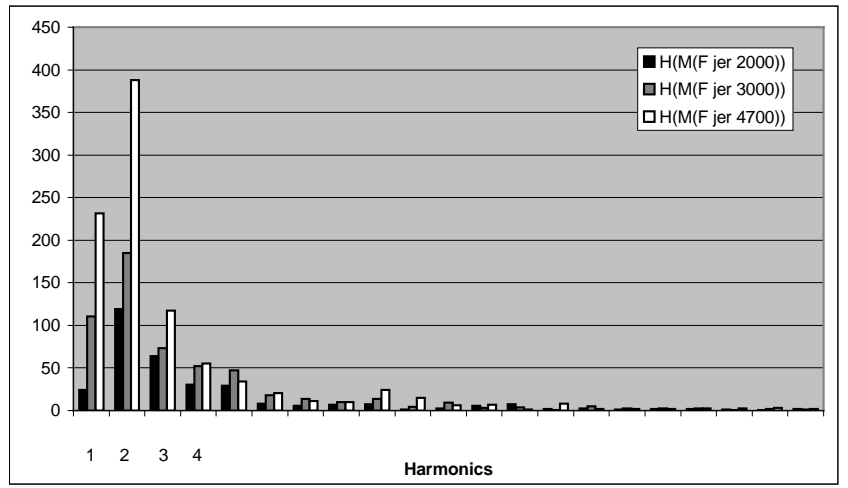

Figure 11 - Compression force harmonics obtained with the actuation set-up presented in figure 3

As an important and versatile technique for the evaluation and prediction of sewing behaviour, this approach provided the basis for the development of a proper feeding efficiency monitoring system. It was developed using the LabView graphical programming language, with specifically designed routines to automatically process, extract and display relevant features, enabling a complete analysis of the displacement and compression force waveforms and the evaluation of feeding efficiency, as a function of the imposed seams quality.

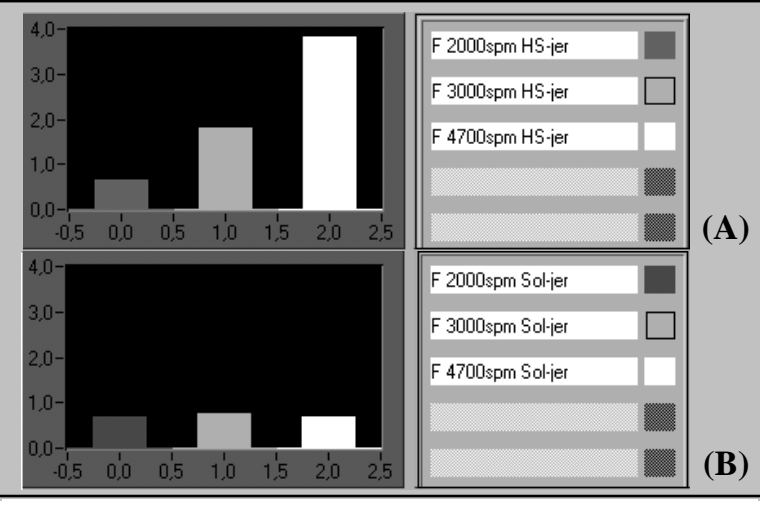

Figure 12 - Harmonic distortion on the obtained waveforms: (A) Using the standard helical spring (HS), and (B) Using the proportional force solenoid (Sol) as figure 3 As reported earlier, decreasing the force applied by the solenoid, using the set-up in figure 3 and two plies of the same jersey fabric, the presser foot bar displacement shows a tendency to increase (see figure 13) and other force variations tend to appear, during and after feeding. Although the THD analysis has proved to be useful to characterise and identify the spring and solenoid actuation, in the latter case, according to the stitch density variations, the distortion changes are quite smaller, being extremely difficult to establish a distortion range to define the quality of the seams (see figure 14). Therefore, recent investigations were directed to derive an adequate method to properly monitor, under any circumstances, the fabrics feeding efficiency. Figure 13 illustrates the Admissible Displacement Limits (ADL), surrounding the $0 \%$ density variation, which establishes the upper and lower presser foot bar displacement limits according to the control values. If any maximum versus 
second displacement coordinate is plotted outside the admissible area, a warning display alerts the operator that the quality of the produced seam will not be the expected one. This method has been used successfully to on-line, and off-line, monitor the feeding efficiency.

\section{CONCLUSIONS}

A new actuation system based on a proportional force solenoid was used replacing the standard spring actuated presser foot bar, aimed at avoiding the presser foot bouncing and lack of fabric control, especially at high speeds. This solution has shown clearly better results regarding the defects on the fabric plies and on the produced seams. THD (Total Harmonic Distortion) and ADL (Admissible Displacement Limits) were presented and discussed as methods for on-line monitoring the feeding

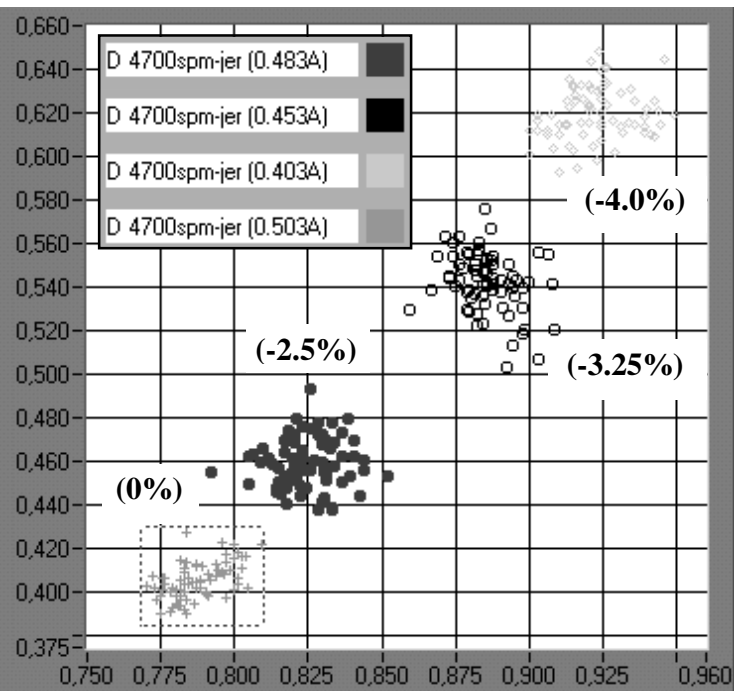

Figure 13 - Maximum versus second (after 260 degrees) displacements (mm) and stitch density variations obtained decreasing the force applied by the solenoid, according to figure 3

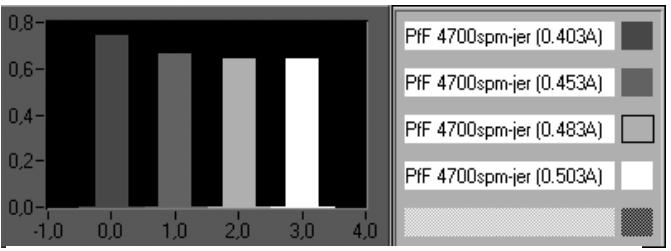

Figure 14 - Harmonic distortion on the obtained compression force waveforms with the solenoid attached as in figure 3 efficiency. ADL have, so far, proved to be a better method. Further research should be undertaken in this area, in order to achieve, in a near future, a closed loop control of the presser foot.

\section{REFERENCES}

1. Rocha, A. M., Ferreira, F. N., Araújo, M., Monteiro, J., Couto, C., Lima, M. F., “Mechatronics in Apparel: Control, Management and Innovation on the Sewing Process", Proceedings of the Mechatronics’96 Conference, Vol. II, pp. 109-114, University of Minho, Guimarães, 1996.

2. Carvalho, M., Ferreira, F. N., "Study of Thread Tensions in an Overlock Sewing Machine", Proceedings of the ViCAM Conference - Vision and Control Aspects of Mechatronics, pp. 223226. University of Minho, Guimarães, 1996.

3. Carvalho, H., Monteiro, J., Ferreira, F. N., "Measurements and Feature Extraction in High-Speed Sewing”, Proceedings of the IEEE: ISIE'97 - International Symposium on Industrial Electronics, Vol. 3, pp. 961-966. University of Minho, Guimarães, 1997.

4. Carvalho, H., Rocha, A. M., Ferreira, F. N., Monteiro, J., “The Development of Support Tools for HighSpeed Sewing Machine Setting, Monitoring and Control”, ISIAC'2000 - Third International Symposium on Intelligent Automation and Control, Maui, Hawaii, USA, June, 2000.

5. Silva, L. F., Lima, M., Ferreira, F. N., Andrade, D., Ferreira, L. P., Couto, C., “Mechatronic Approach to the Feeding System of an Overlock Sewing Machine”. Mechatronics Journal, 9, 817-842, 1999.

6. Silva, L. F., Lima, M., Ferreira, F. N., Coelho, J., Couto, C., "Development of a Mechatronic Controlled Actuation on the Presser Foot of an Overlock Sewing Machine”, Proceedings of the 44th International Scientific Colloquium, Vol. 2, pp. 116-121. Technical University of Ilmenau, Germany, 1999. 